\title{
The p53 family grows old
}

\author{
Elsa R. Flores ${ }^{1,3}$ and Guillermina Lozano ${ }^{2,3}$ \\ ${ }^{1}$ Department of Biochemistry and Molecular Biology, ${ }^{2}$ Department of Genetics, The Graduate School of Biomedical Sciences, \\ The University of Texas MD Anderson Cancer Center, Houston, Texas 77030, USA
}

p73 and p63 are evolving members of the p53 tumor suppressor family. TAp73 is a p73 isoform with a potent transcriptional activation domain, and loss of TAp73 predisposes mice to tumor development. In this issue of Genes \& Development, Rufini and colleagues (pp. 20092014) discuss how TAp73-null mice display an aging phenotype that is due to mitochondrial dysfunction. Specifically, decreased levels of cytochrome $C$ oxidase subunit 4 isoform 1 (Cox4i1) impair cytochrome C oxidase (COX) function, the multimeric enzyme that executes the last step in aerobic respiration. An emerging theme is that defects in metabolism account for both cancer and aging.

Aging is characterized by a functional decline in the cells and tissues in an animal and the reduced ability to appropriately respond to environmental insults, resulting in deterioration of the overall fitness of the organism. Aging and the development of cancer are intimately tied, since the majority of cancers develop after the age of 50. Many other diseases associated with aging are also tightly linked to the development of cancer, including metabolic disorders such as diabetes and obesity. Therefore, an aging organism is the ideal environment for tumor development with the accumulation of cellular genetic alterations, the inability to respond to genotoxic stress, and the inability to properly regulate metabolic cues. In contrast, aging can also play a protective role in cancer. As cells age, their ability to proliferate decreases and they undergo senescence. This loss of cellular proliferation can protect from the formation of a tumor by keeping damaged cells from multiplying. Although the phenotypes of aging organisms have been well characterized, the molecular mechanisms tying longevity to metabolism and cancer are still largely unknown. The use of genetically engineered animal models, such as those with mutations in tumor suppressor genes, has enabled the identification of genes and pathways associated with aging, metabolism, and cancer. The dichotomous roles of aging in cancer can more easily be explored and the mechanisms controlling the aging process can be un-

[Keywords: p73; p53; aging; senescence; metabolism; ROS; mitochondria] ${ }^{3}$ Corresponding authors

E-mail gglozano@mdanderson.org

E-mail elsaflores@mdanderson.org

Article is online at http://www.genesdev.org/cgi/doi/10.1101/gad.202648.112. derstood by examining various tissues in mice harboring the same mutation but with different proliferative and metabolic capacities.

\section{TAp73 suppresses premature aging and cancer}

In this issue of Genes \& Development, Rufini et al. (2012) describe a premature aging phenotype in TAp73-null mice and implicate mitochondrial dysfunction as the root cause. $p 73$, a gene related to the $p 53$ tumor suppressor, encodes multiple isoforms. TAp73-null mice lack expression of the TAp73 isoform (the isoform that contains the major transactivation domain) but retain expression of the $\Delta \mathrm{Np} 73$ isoform (Tomasini et al. 2008). TAp $73^{-1-}$ mice are generally viable but tumor-prone (Tomasini et al. 2008).

Approximately $30 \%$ of TAp 73 heterozygous and $73 \%$ of TAp73-null mice develop tumors, with 32\% of TAp73null mice developing lung adenocarcinomas (Tomasini et al. 2008). The remaining tumor-free TAp73-null mice show premature aging phenotypes, as measured by various parameters: decreased survival, weight loss, decreased body fat, kyphosis (a curvature of the spine), thin skin, and corneal degeneration. Compared with wild-type agematched animals, these mice also show decreased hair growth after shaving. A molecular analysis indicates that the lungs and hearts of TAp73-null mice have increased expression of $p 16$, a marker associated with aging. Last, the livers and kidneys from TAp73-null mice show increased levels of oxidized proteins, as measured by immunoblotting of carbonyl groups. These phenotypes are the biological manifestations of aging in an organism.

Mouse embryo fibroblasts (MEFs) generated from TAp73null mice also show a dramatic loss of proliferation with increased $\beta$-galactosidase activity (a marker of replicative senescence) as compared with normal MEFs. p16 and p19, which are often increased in senescence, are also upregulated in TAp73-null MEFs. Thus, both in vivo and in vitro data convincingly support an aging phenotype upon loss of TAp73.

\section{The $\mathbf{p} 53$ family in aging}

Many of the premature aging phenotypes observed in the $T A p 73^{-/-}$mice are reminiscent of those identified in TAp63 ${ }^{-1-}$ mice (Su et al. 2009) and in one p53 mutant model (Tyner et al. 2002). All three models develop kyphosis and alopecia. Like the TAp73-/- mice, the TAp $63^{-/-}$ 
mice also have premature thinning of the skin. The skin and hair loss phenotypes in the TAp $63^{-/-}$mice are due to the premature senescence and depletion of stem cells known as SKPs (skin-derived precursors). Whether the thinning skin and alopecia in the $T A p 73^{-1-}$ mice are due to a similar stem cell defect is not known.

p53 aging models are much more complex. In contrast to loss-of-function alleles in the TAp63 and TAp73 mice that result in aging, $p 53$-null mice do not exhibit aging defects. However, this may be due to the fact that all p53null mice develop tumor phenotypes and die by $8 \mathrm{mo}$ of age. Interestingly, though, mice expressing a truncated mutant $p 53$ allele (labeled $p 53 M$ ) that exhibits increased $p 53$ activity also shows aging defects. $p 53^{+} / M$ mice exhibit kyphosis, loss of body mass, muscle atrophy, and loss of adipose tissue. On the other hand, mice with three p53 copies (super p53 mice) or those with increased p53 activity due to partial loss of its inhibitor, $\mathrm{Mdm} 2$, show no aging defects (Garcia-Cao et al. 2002; Mendrysa et al. 2006). Perhaps p63 and p73 play important roles in the aging phenotypes of $p 53 M$ mice. Both TAp63 and TAp73 bind mutant forms of p53 (Gaiddon et al. 2001) and may bind the wild-type p53/p53M protein complex, thus depleting cells of both TAp63 and TAp73. Despite the controversy, these data point to important roles of the p53 family members in aging phenotypes in mice.

\section{TAp73 regulates mitochondrial metabolism}

Oxidative damage is associated with senescence in culture and aging in vivo. Rufini et al. (2012) therefore set out to determine whether TAp73-null MEFs are sensitive to oxidative damaging agents such as hydrogen peroxide $\left(\mathrm{H}_{2} \mathrm{O}_{2}\right)$. TAp73-null MEFs were much more sensitive to death induced by $\mathrm{H}_{2} \mathrm{O}_{2}$ treatment than normal MEFs. On the other hand, TAp73-null MEFs grow well in low-oxygen conditions or with the addition of antioxidants, conditions that dampen oxidative damage.

Mitochondria play a vital role in oxidative metabolism. One of the telltale signs of decreasing mitochondrial function is an increase in reactive oxygen species (ROS). TAp $73^{-/-}$MEFs clearly accumulate high levels of ROS, thus implicating mitochondrial dysfunction in the aging phenotype of TAp73-null mice.

To directly determine whether there are defects in mitochondrial metabolism, Rufini et al. (2012) measured aerobic respiration and found that TAp73-null MEFs have decreased rates of oxygen consumption. Oxygen consumption was also reduced in vivo in lung and kidney tissues from mice lacking TAp73. A measurement of mitochondrial enzymatic activity revealed defects in cytochrome $\mathrm{C}$ oxidase (COX), a multimeric enzyme that functions in the last step of the electron transfer chain. Importantly, siRNA-mediated knockdown of TAp73 in human cells recapitulates many of these phenotypes.

A more in-depth analysis of the mitochondrial defect in TAp73-null MEFs showed decreased expression of the nuclear Cox4i1 gene, which encodes the COX subunit 4 isoform 1. COX is a multimeric protein complex composed of 13 subunits embedded in the mitochondrial membrane that catalyzes the transfer of electrons from cytochrome $\mathrm{C}$ to oxygen. It consists of a core of three proteins and 10 associated factors (like Cox4i1), which are encoded in the nucleus and help to regulate structure and modulate enzymatic activity. Rufini et al. (2012) zeroed in on Cox4i1 since it shows decreased expression in arrays of $p 73$-null MEFs compared with wild-type MEFs (Lin et al. 2009). An additional series of experiments verified these data and showed that Cox4i1 is less abundant in TAp73-null MEFs and tissues and that TAp73 binds specifically to two response elements in the Cox4i1 promoter. Again, TAp73 knockdown in human cells reproduced the effects on Cox4i1. Last, ectopic expression of TAp73 allows up-regulation of Cox4i1. The studies came full circle when Rufini et al. (2012) showed that downmodulation of Cox4i1 reduces oxygen consumption and increases $\mathrm{H}_{2} \mathrm{O}_{2}$-induced cell death. Additionally, Cox $4 i 1$ knockdown in wild-type MEFs also reproduced the senescent phenotype. Thus, the investigators have pinpointed defects in a specific protein of the COX complex, which dampens mitochondrial function and results in aging phenotypes in vivo and in vitro.

Premature aging is often accompanied by defects in lipid and glucose metabolism. To determine whether the TAp $73^{-/-}$mice had defects in these processes, Rufini et al. (2012) challenged the TAp73 ${ }^{-1-}$ mice with high-fat $\operatorname{diet}$ (HFD) food for $16 \mathrm{wk}$. Using an intraperitoneal glucose tolerance test (IPGTT) and an intraperitoneal insulin tolerance test (IPITT), they demonstrated that the TAp $73^{-/-}$mice fed a HFD gain less weight than wildtype mice and are protected from glucose intolerance and insulin resistance. This interesting result shows that ROS and insulin resistance can be uncoupled and that the effect in the TAp $73^{-/-}$mice may be due to the positive effects of ROS on insulin signaling. This is thought to occur, in part, through the oxidative inhibition of protein tyrosine phosphatase 1B (PTP1B), which negatively regulates insulin action (Goldstein et al. 2005). The uncoupling of premature aging and lipid and glucose metabolism in the $T A p 73^{-1-}$ mice makes it an ideal in vivo model to identify the molecular mechanisms regulated by ROS in aging and cancer without the perturbations in pathways that control lipid and glucose metabolism.

\section{Metabolic regulation is a key function for tumor suppression by $\mathbf{p} 53$}

Defects in metabolic regulation have long been thought to be associated with cancer (Warburg 1956). A recent study demonstrated that the regulation of metabolism is critical for the suppression of tumorigenesis by p53. Gu's laboratory (Li et al. 2012) created a p53 mutant mouse (p53 3KR) that fails to induce downstream transcriptional targets critical for apoptosis, such as PUMA, and those critical for senescence, such as $p 16$ and $P M L$. Even with these defects in transcriptional function, p53 retains its tumor-suppressive functions, and the p53 3KR mice are markedly tumor-resistant. The mechanism for this tumor resistance is through the ability of p53 3KR to transactivate GLS2, which encodes an enzyme that regulates 
glutamine utilization and promotes mitochondrial respiration and ATP generation. Reintroduction of GLS2 in H1299 cells, a lung adenocarcinoma cell line lacking p53, resulted in the formation of fewer colonies in transformation assays. These data indicate that the transcriptional regulation of mitochondrial function by p53 is critical for its tumor-suppressive function and suggest that TAp73 may have a similar function through regulation of target genes like Cox4i, another critical enzyme in mitochondrial respiration. Since $p 53$ 3KR mice appear to have intact mitochondrial function, it seems unlikely that they will age prematurely. A p53 mutant mouse with defects specifically in metabolic function may shed light on this issue.

\section{Similarities between phenotypes of the TAp73-null and TAp63-null mice}

As indicated, TAp73-null mice are susceptible to cancer and early aging. The TAp $63^{-/-}$mice are also tumor-prone and develop metastatic mammary adenocarcinoma, lung adenocarcinomas, and squamous cell carcinomas (Su et al. 2010). Additionally, the TAp63 $3^{-/}$mice have some of the same premature aging defects as the TAp $73^{-/-}$ mice: thinning skin, alopecia, and kyphosis (Su et al. 2009). Clearly, TAp73 regulates a specific gene encoding a protein of the COX complex that functions in aerobic respiration in the mitochondria. Whether the TAp63-null mice have mitochondrial defects and whether TAp63 also regulates the Cox4i gene is currently unknown. Given the differences in tissue distribution of p63 and p73 expression and the fact that genetically engineered mice for these genes have different developmental and tumor phenotypes, TAp63 likely works through a different pathway. If, however, TAp63-null mice have defects in some aspect of mitochondrial function, a theme that may evolve is that mitochondrial dysfunction in any organ compromises the entire organism.

Analyses of TAp63-null mice clearly show a role for TAp63 in stem cells (Su et al. 2009). In TAp63 ${ }^{-1-}$ mice, the aging phenotype in the skin was found to be due to a hyperproliferation of stem cells within the skin (Su et al. 2009). Similarly, p53M mice with associated aging phenotypes have stem cell defects (Dumble et al. 2007). Lategeneration telomerase-deficient mice show aging defects as well, but mice lacking $p 53$ in a background of telomere attrition show improved wound healing, hair growth, and skin renewal (Sahin et al. 2011). In the skin, in particular, there was an increase in the number of epidermal stem cells. Thus, at least two family members (p53 and p63) regulate stem cell functions associated with aging. A precedent for a role for $\mathrm{p} 73$ in the maintenance of stem cells exists in the brain. p73 has been identified as key to maintaining neural stem cells in quiescence through the transcriptional regulation of target genes that control proliferation and asymmetric cell division, including Hey2 (Fujitani et al. 2010; Talos et al. 2010). The stem cell defect seen in p 73 mutant mice may be the main cause of neurodegenerative diseases like Alzheimer's that have been linked to $\mathrm{p} 73$ (Wetzel et al. 2008). Further investiga- tion of p73's function in stem cells will likely unveil other molecular mechanisms involved in longevity.

\section{Conclusions and future directions}

The p53 family has emerged as a family of transcription factors that plays critical roles in controlling longevity. Given the complexity of the p53 family and its numerous isoforms and differences in tissue expression among the family members, it will be critical to understand the p53 family complexes that transcriptionally regulate processes like metabolism using ChIP-seq (chromatin immunoprecipitation [ChIP] coupled with deep sequencing) and RNA-seq (RNA sequencing) experiments in different tissues. With the new genetically engineered mouse models lacking various isoforms of the p53 family, such as the $T A p 73^{-1-}$ mice used in this study, there are numerous opportunities to probe p53 family complexes in cells and stem cells of metabolic tissues in these mice. Previous studies have already implicated the p53 family in the regulation of genes other than Cox4i in oxidative phosphorylation (Lin et al. 2009). The roles of metabolism in cancer are still an area of intense investigation. The future holds many possibilities to unlock the molecular mechanisms of aging, metabolism, and cancer through understanding the processes controlled by the p 53 family.

\section{References}

Dumble M, Moore L, Chambers SM, Geiger H, Van Zant G, Goodell MA, Donehower LA. 2007. The impact of altered p53 dosage on hematopoietic stem cell dynamics during aging. Blood 109: 1736-1742.

Fujitani M, Cancino GI, Dugani CB, Weaver IC, Gauthier-Fisher A, Paquin A, Mak TW, Wojtowicz MJ, Miller FD, Kaplan DR. 2010. TAp73 acts via the bHLH Hey2 to promote long-term maintenance of neural precursors. Curr Biol 20: 2058-2065.

Gaiddon C, Lokshin M, Ahn J, Zhang T, Prives C. 2001. A subset of tumor-derived mutant forms of p53 down-regulate p63 and p73 through a direct interaction with the p53 core domain. Mol Cell Biol 21: 1874-1887.

Garcia-Cao I, Garcia-Cao M, Martin-Caballero J, Criado LM, Klatt P, Flores JM, Weill JC, Blasco MA, Serrano M. 2002. 'Super p53' mice exhibit enhanced DNA damage response, are tumor resistant and age normally. EMBO I 21: 62256235.

Goldstein BJ, Mahadev K, Wu X, Zhu L, Motoshima H. 2005. Role of insulin-induced reactive oxygen species in the insulin signaling pathway. Antioxid Redox Signal 7: 1021-1031.

Li T, Kon N, Jiang L, Tan M, Ludwig T, Zhao Y, Baer R, Gu W. 2012. Tumor suppression in the absence of p53-mediated cell-cycle arrest, apoptosis, and senescence. Cell 149: 12691283.

Lin YL, Sengupta S, Gurdziel K, Bell GW, Jacks T, Flores ER. 2009. p63 and p73 transcriptionally regulate genes involved in DNA repair. PLoS Genet 5: e1000680. doi: 10.1371/journal. pgen.1000680.

Mendrysa SM, O'Leary KA, McElwee MK, Michalowski J, Eisenman RN, Powell DA, Perry ME. 2006. Tumor suppression and normal aging in mice with constitutively high p53 activity. Genes Dev 20: 16-21.

Rufini A, Niklison-Chirou MV, Inoue S, Tomasini R, Harris IS, Marino A, Federici M, Dinsdale D, Knight RA, Melino G, 
et al. 2012. TAp73 depletion accelerates aging through metabolic dysregulation. Genes Dev (this issue). doi: 10.1101/ gad.197640.112.

Sahin E, Colla S, Liesa M, Moslehi J, Muller FL, Guo M, Cooper M, Kotton D, Fabian AJ, Walkey C, et al. 2011. Telomere dysfunction induces metabolic and mitochondrial compromise. Nature 470: 359-365.

Su X, Paris M, Gi YJ, Tsai KY, Cho MS, Lin YL, Biernaskie JA, Sinha S, Prives C, Pevny LH, et al. 2009. TAp63 prevents premature aging by promoting adult stem cell maintenance. Cell Stem Cell 5: 64-75.

Su X, Chakravarti D, Cho MS, Liu L, Gi YJ, Lin YL, Leung ML, El-Naggar A, Creighton CJ, Suraokar MB, et al. 2010. TAp63 suppresses metastasis through coordinate regulation of Dicer and miRNAs. Nature 467: 986-990.

Talos F, Abraham A, Vaseva AV, Holembowski L, Tsirka SE, Scheel A, Bode D, Dobbelstein M, Bruck W, Moll UM. 2010. p73 is an essential regulator of neural stem cell maintenance in embryonal and adult CNS neurogenesis. Cell Death Differ 17: 1816-1829.

Tomasini R, Tsuchihara K, Wilhelm M, Fujitani M, Rufini A, Cheung CC, Khan F, Itie-Youten A, Wakeham A, Tsao MS, et al. 2008. TAp73 knockout shows genomic instability with infertility and tumor suppressor functions. Genes Dev 22: 2677-2691.

Tyner SD, Venkatachalam S, Choi J, Jones S, Ghebranious N, Igelmann H, Lu X, Soron G, Cooper B, Brayton C, et al. 2002. p53 mutant mice that display early ageing-associated phenotypes. Nature 415: 45-53.

Warburg O. 1956. On the origin of cancer cells. Science 123: 309-314.

Wetzel MK, Naska S, Laliberte CL, Rymar VV, Fujitani M, Biernaskie JA, Cole CJ, Lerch JP, Spring S, Wang SH, et al. 2008. p73 regulates neurodegeneration and phospho- $\tau$ accumulation during aging and Alzheimer's disease. Neuron 59: 708-721. 


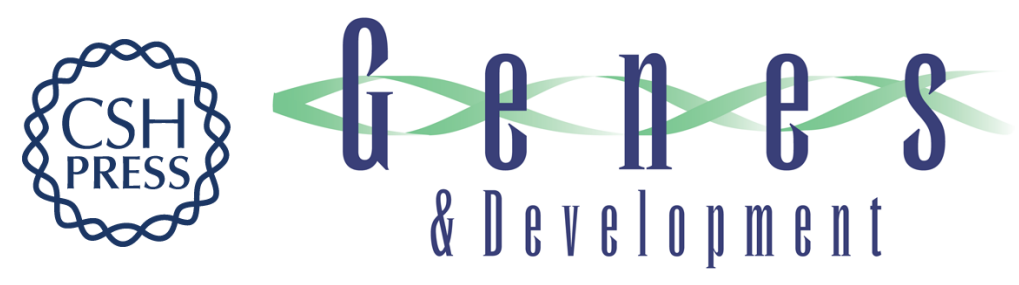

\section{The p53 family grows old}

Elsa R. Flores and Guillermina Lozano

Genes Dev. 2012, 26:

Access the most recent version at doi:10.1101/gad.202648.112

Related Content TAp73 depletion accelerates aging through metabolic dysregulation Alessandro Rufini, Maria Victoria Niklison-Chirou, Satoshi Inoue, et al. Genes Dev. September , 2012 26: 2009-2014

References This article cites 16 articles, 6 of which can be accessed free at: http://genesdev.cshlp.org/content/26/18/1997.full.html\#ref-list-1

Articles cited in:

http://genesdev.cshlp.org/content/26/18/1997.full.html\#related-urls

\section{License}

Email Alerting

Receive free email alerts when new articles cite this article - sign up in the box at the top Service right corner of the article or click here.

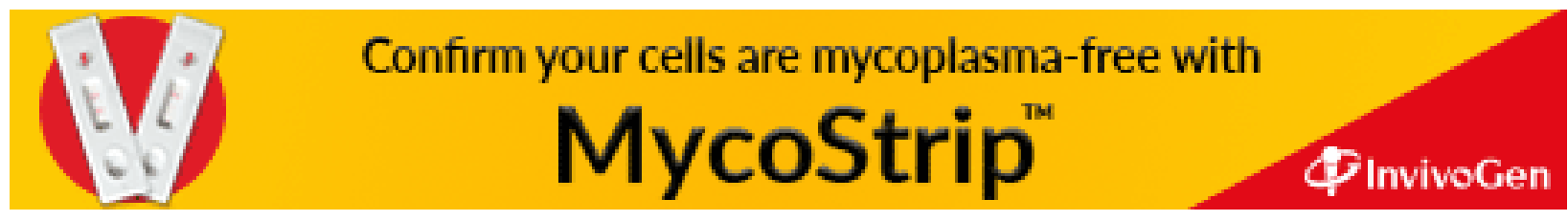

